\title{
Framing smallholder inclusion in global value chains - case studies from India and West Africa
}

\author{
M. Franz ${ }^{1}$, M. Felix ${ }^{2}$, and A. Trebbin ${ }^{3}$ \\ ${ }^{1}$ Universität Osnabrück, Institut für Geographie, Seminarstr. 19a/b, 49074 Osnabrück, Germany \\ ${ }^{2}$ WiN=WiN Agency, Schuhstr. 4, 73230 Kichheim/Teck, Germany \\ ${ }^{3}$ Philipps-Universität Marburg, Fachbereich Geographie, Deutschhausstr. 10, 35032 Marburg, Germany \\ Correspondence to: M. Franz (martin.franz@uni-osnabrueck.de)
}

Received: 2 April 2013 - Revised: 2 February 2014 - Accepted: 11 February 2014 - Published: 11 December 2014

\begin{abstract}
A resurrected interest in agriculture has brought in its wake growing interest in smallholders in the global South by scholars, companies, governments and development agencies alike. While non-governmental organisations and development agencies see the potential to reduce poverty, companies look upon smallholder agriculture as a widely untapped resource for the sourcing of crops and as a sales market for agricultural inputs. While the important role of large corporate buyers of agricultural produce as lead firms in value chains is often discussed and emphasised, the power of providers of technology and agricultural inputs is being rather neglected. In this paper, we analyse two case studies of technology and input providers in agricultural value chains and their role in smallholder inclusion with the aim of finding out how such companies impact the governance of the value chains. To do so we combine insights from the value chain literature with the concept of framing/overflowing.
\end{abstract}

\section{Introduction}

"As demand for agricultural products rises around the world, partnering with the smallholder farming sector offers agribusiness companies significant opportunities to grow their own businesses" (GIZ, 2012:7). This statement from a guide book for agribusiness companies shows the current trend. In recent decades, the development of agriculture had lost the attention of the public as well as of economic and political decision makers. The food crisis of 2007 and 2008 brought the topic back on the agenda. In this new wave of interest, a special focus has been put on smallholders. With growing world population and an increasing scarcity of resources, supporting smallholder agriculture has become crucial for increasing agricultural productivity. Helping smallholders integrate themselves into modern domestic or even global value chains is an important part of this strategy, which ultimately results in the commercialisation of smallholder farming.

In this field, a wide range of collaborative arrangements between large-scale investors, farmers and communities has developed since the 1990s. Examples are "shared ownership of key assets, formalised joint ventures, profit-sharing ar- rangements, contract farming or local content schemes, community land leases and management contracts, or local service agreements" (Vermeulen and Cotula, 2010:14). Considerable business opportunities lay in such arrangements. Thus, companies do not only engage in smallholder value chain inclusion in order to source products; they also identify farmers, small-scale processors and middlemen as a remunerative sales market for their products and services. The bottom of the pyramid approach (BoP) puts an emphasis on the poorest (Prahalad, 2012), viewing them as the biggest potential for a growing market. The BoP suggests that companies should invest in this market segment so that economic growth can be assured (UNDP, 2008). This is viewed as a win-win scenario (Prahalad, 2006) because the poor benefit by getting access to knowledge, innovation, technology and services. In addition, the poor are able to overcome the socalled "BoP penalty" (Hammond et al., 2007:25), which is the higher price for goods and services that poor consumers often have to pay, "either in cash or in the effort they must expend to obtain [the same products]" compared to wealthier consumers (Hammond et al., 2007:25). The trend of identifying smallholders as a market brings together a wide range of 
companies from different sectors that want to integrate smallholders in the value chain. All of these companies can potentially influence the governance and coordination structure of the respective value chains.

The potential impact of agricultural and technological companies on the governance and coordination of value chains is, to date, widely neglected in most of the value chain literature. The existing literature tends "to emphasize the impact of lead firms (especially large retailers and manufacturers located in core centres of the world economy) in determining the governance structure of a given chain. [...] It tends to downplay the agency of other actors [...] in shaping the governance structure, upgrading possibilities, and unequal distribution of value associated with particular chains" (Hough, 2011:1017). With this paper, we intend to address this gap by focusing on companies that shape agrifood value chains without actually trading agricultural produce. With two case studies, the paper aims at analysing how input and technology providers can frame smallholder value chain inclusion and how they gain influence over the governance and coordination structure of agricultural value chains. We want to shed light on this subject by combining insights from the value chain literature with the concept of framing/overflowing (Callon, 1998).

The first case study analyses Bayer's Food Chain Partnership (FCP) in India. It is based on 30 qualitative interviews that were conducted in 2008, 2011 and 2012 with representatives of food retail and processing companies, their supply chain staff in rural areas, the agrochemical company Bayer CropScience and five smallholder farmer groups. The second case study deals with the activities of the company SAP as a technological partner of the African Cashew Initiative. This case study is based on the evaluation of the 2012 piloting cycle. It considers 17 qualitative interviews with representatives of participating farmer associations and a diverse set of expert interviews conducted in 2011 and 2012. Furthermore, it is substantiated with an analysis of transactional data. Before we turn to the case studies, we will give an insight into the conceptual frameworks that we will use for the analysis.

\section{Governing smallholders' inclusion in global value chains}

During the last two decades, a growing field of studies in economic geography and related disciplines has evolved which deal with the production, trade and consumption of goods (Oro and Pritchard, 2011). This includes approaches like the global value chains (GVC; e.g. Gereffi et al., 2005) and the global production networks (GPN; e.g. Henderson et al., 2002). The main difference between GPN and GVC is the (spatial) scope of aspects examined in relationships or transactions. GVC focuses mainly on inter-firm relationships, and GPN has a stronger emphasis on spatial aspects through the concept of embeddedness. Spatial aspects in- clude "[...] how places are being transformed by flows of capital, labour, knowledge, power etc. and how, at the same time, places [...] are transforming those flows as they locate in place-specific domains" (Henderson et al., 2002:438). The GVC approach is used primarily for the linear analysis of governance structures between companies and their institutional context. The GPN approach is meant "to go beyond such linearity to incorporate all kinds of network configuration" (Coe et al., 2008:272). This includes actors like consumers, non-governmental organisations (NGOs) and trade unions. This inclusion is important since smallholder inclusion schemes "often work with non-traditional partners [...], including governments, NGOs, donors, academic institutions and the media" (GIZ, 2012:60).

Most of the discussions about GVC or GPN focus on power or governance structures. In studies on agri-food production networks, this analysis is usually limited to the relationships between primary producers, middlemen, processors and retail chains. The potential role of input suppliers in shaping the structure of agri-food networks is often underestimated. Even though the providers of fertilisers, pesticides, seeds or technology/machinery are often mentioned in GVC/GPN studies, they are widely conceptualised as subordinates, who depend on the orders of producers or lead firms. In particular, studies on the implementation of quality standards (e.g. Lee et al., 2012) or contract farming (e.g. Dannenberg and Nduru, 2013) emphasise the lead firms' ability to enforce requirements of specified inputs.

The GVC framework (Gereffi et al., 2005) distinguishes between five types of governance (market, modular, relational, captive, hierarchy) executed by lead firms. In each governance type, lead firms take more or less direct control over production processes. Hence, the effect of the various governance structures on downstream actors, such as farmers, varies. As shown in Fig. 1, governance types, which are characterised by a low degree of direct coordination by lead firms, can include purchase from the open market or a simple purchase agreement. Another extreme of organising an agricultural value chain is represented by captive and hierarchical forms of governance, where lead firms control a major part of the production process and, as in the case of land grabbing, may even own the land upon which the crops are produced. In between these extremes lie possibilities for more collaborative arrangements that link farmers with agribusinesses (Vermeulen and Cotula, 2010; Kubzansky et al., 2011; GIZ, 2012). Here different arrangements involve various levels of coordination or vertical integration. The levels of vertical integration are strongly linked to the question of land ownership since it is an important determinant for choosing the respective arrangement (see Fig. 1).

Scholars favouring the GVC approach would use the Gereffi et al. (2005) fivefold typology of governance to analyse different arrangements, but as Ponte and Gibbon (2005:6) point out, different "[...] forms of coordination may exist at different links in the same value chain. These categories 


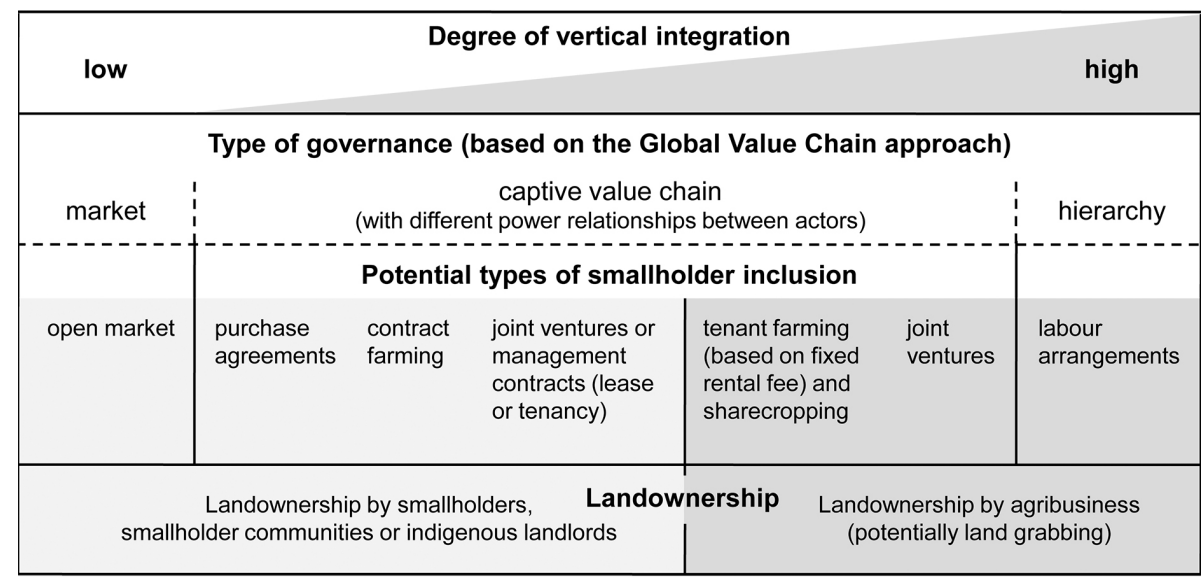

Figure 1. Smallholder inclusion in agribusiness value chains - vertical integration, types of governance and landownership (authors' own figure based on Gereffi et al., 2005:89; Vermeulen and Cotula, 2010:14, 32; GIZ, 2012:54).

do not characterize the governance of the overall chain. It is thus necessary to distinguish 'immediate' forms of coordination from the overall mode of governance." While companies that build up their value chains may aim at a specific type of coordination for the whole chain, the reality is often much more complex.

Parallel to the academic debate about value chain governance and the lead firms' roles in these processes, a large number of studies, policy papers and guidebooks have been developed in recent years that view the value chain approach as a development concept (e.g. USAID, 2010; UNIDO, 2011). In addition, they emphasise the potential business opportunities in exploring farmers in the global South as a promising market for buyers of agricultural produce and input providers (e.g. UNDP, 2008; GIZ, 2012). In this body of literature, elements of the analytical tools are used as models to configure supply chains from the global South to the North. Berndt and Boeckler (2011:1068) put it this way: "It has been yet another species of 'economists in the wild' which has taken these efforts as a starting point to organize chain-like production whether referred to as value, commodity or supply chains transnationally and efficiently: the practitioners of supply-chain management [...]".

In recent years, development agencies and multinational institutions have published a number of manuals (e.g. GIZ, 2012) and best practice cases (e.g. FAO, 2011) for companies that want to pursue business relations with smallholders in the global South in order to integrate them into their value chains. Companies, NGOs and development agencies have already implemented a number of such projects. They include a range of activities contributing to the development of real-life value chains in such a way that they actually resemble the theoretical approaches. This includes activities aiming to

- upgrade smallholders: since many smallholders are often unable to fulfil the qualitative and quantitative re- quirements of buyers, many projects aim to improve the capacity of smallholders by investing in their training (see case study 1 ), technology (see case study 2 ) or irrigation (GIZ, 2012).

- improve access to agricultural services: this lack of access often limits the possibilities of smallholders to upgrade their production skills and to fulfil the standards demanded by buyers (see case study 1; Trebbin and Franz, 2010);

- upgrade the middlemen: coordinating direct and frequent contact to a large number of smallholders is costly and time-intensive. It is also not buyers' core business. Thus, upgrading the middlemen helps to fulfil the buyers' qualitative and quantitative requirements and provides value-added services like grading, packaging and logistics (Dannenberg and Nduru, 2013);

- organise smallholders: as dealing with individual smallholders is often difficult and costly for companies, many projects assist in the development of farmer organisations and their integration into value chains (see case study 2). Smallholder organisations improve farmers' bargaining power by creating economies of scale in input purchases and output sales (Trebbin and Hassler, 2012);

- improve access to financial services: in the early stages of value chain integration, smallholders are often linked to the formal financial sector (see case study 2). This allows them to make investments, to open bank accounts in order to formalise payments and to free themselves from their dependence on local money lenders;

- improve infrastructure: the inclusion of smallholders into value chains is often limited by a lack of transport infrastructure, warehouses and cold chain facilities. 
This lacuna is targeted by projects; some are realised through public-private partnerships (FAO, 2012; World Bank, 2007).

Since the many on-ground realities often act unexpectedly, irrationally and imperfectly, concepts and models are obviously not always easily applied. This real-life diversity also causes scepticism of GPN advocates towards the GVC governance typology. They "point to the complexity and richness of on-the-ground governance processes" (Coe, 2011:7). This is especially true in the agri-food sector in the global South. In many of these countries, agriculture and trade structures are manifold and highly fragmented. When, in such contexts, development agencies apply the theoretical framework from the value chain inclusion theory, it is important to consider why the governance in such value chains cannot always be executed as suggested by the given theory. Here Callon's (1998:244) concepts of "performativity", "framing" and "overflowing" give interesting insights.

Seen from Callon's perspective, the debate on value chains in the agri-food sector can be characterised as performative because it "contributes to the construction of the reality that it describes" (Callon, 2007:316). In reality, academic theories and approaches are applied as "projects that transform the world" (Berndt and Boeckler, 2011:1059) in which researchers act as consultants to firms, governments and donors. The actors' tacit agreements with these ideas are defined by Callon (1998:249 referring to Goffman, 1971) as the "frame". It "establishes a boundary within which interactions - the significance and content of which are self-evident to the protagonists - take place more or less independently of their surrounding context" (Callon, 1998:249).

Callon (1998) refers to the described behaviour of the real world not sticking to the model frame as overflowing. The concept highlights "the omnipresence of connections with the outside world and the irrepressible and productive overflows which the latter encourage" (Callon, 1998:250). Overflowing can take the form of positive or negative externalities occurring during the implementation of the theoretical model in the real world (Callon, 1998). In smallholder GVC inclusion, negative externalities may be the ecological impacts of intensified agriculture or the adverse position of farmers who are excluded from the chain. A positive externality may be the spread of agricultural knowledge beyond the farmers who are included in the chain. From this point of view, "externalities are simply the results of imperfections or failures in the framing process" (Callon, 1998:251).

Berndt and Boeckler (2011) utilise the concept of framing and overflowing for a GVC analysis. In their work, the term overflowing describes processes of contesting and resisting the mainstream model. In this case, affected groups do not accept the framed rules as given and unalterable. For actors who view framing as desirable, "overflows are exceptions which must be contained and channelled with the help of appropriate investments" (Callon, 1998:250).
In the context of smallholder agriculture and its market relations, it seems like "overflowing is the rule; that framing when present at all - is a rare and expensive outcome" (Callon, 1998:252). For example, Dannenberg (2011) showed how farmers and middlemen in Kenya cause horizontal fragmentation of the value chain including its designated governance structures by circumventing the GLOBALG.A.P. standard - a private standard for food that has become quasimandatory for horticultural farmers producing for the EU market - to prevent value chain exclusion. This shows how overflowing can limit the success of the respective companies to frame the value chain.

The framing of agricultural value chains in the global South can become very costly because, as Callon (1998:256) declares, in various fragmented on-the-ground realities "overflows happen all the time, since they are fed by multiple sources and flow down multiple channels". A strong fragmentation in landownership and trade structures and the high degree of informality make it difficult for companies to source agricultural produce. They need to embed themselves into a business environment with which they are often unfamiliar. Many large transnational companies who want to source directly from smallholders lack network embeddedness (cf. Hess, 2004) when dealing with smallholders or farmer organisations. This results in a lack of trust and strong overflows. On the other hand, network embeddedness is often problematic for the marginalised population in remote areas because their location determines their inclusion or exclusion from the GPN. This has potential to worsen their BoP penalty.

Not being able to build up integrated value chains with smallholders is especially problematic for companies in respect to the ever-increasing importance of private standards and the inherent traceability of produce. Both factors are very important for coordinating value chains and enforcing framing. Traceability assures that the origin can be identified and the farmer sanctioned if a standard has been violated (overflowing) (Germain, 2003). Technology helps to trace produce and to enforce stringent quality standards. Consequently, companies that offer this kind of technological solution can have an important and powerful position. However, long transnational agricultural value chains, that integrate several actors, make it difficult to prevent overflows and to assure strict quality control at all levels (Lee et al., 2012). As a result, standard compliance plays an important role in value chain management. Since stringent requirements, such as standards, represent GVC entry barriers for smallholders, the capacity to fulfil or bypass them is essential for smallholders (Ouma, 2010; Dannenberg, 2011). The following case studies address this point, which has been barely covered in the value chain governance debate. 


\subsection{Case study 1: Bayer's Food Chain Partnership in India}

In India, $82 \%$ of land holdings are smaller than 2 ha (Government of India, 2010). Retailers and food processors have to include smallholders in their value chains if they want to avoid the traditional supply network. However, it is hard for smallholders to fulfil the companies' requirements. Bayer CropScience (BCS) responded to these obstacles with its Food Chain Partnership (FCP) programme, which has been implemented in more than 30 countries (GIZ, 2012:60). In 2007 , BCS started to connect with various retailers, processors and fruit and vegetable exporters in India. It also began to upgrade farmers, improve their access to agricultural services and integrate them into the value chains of cooperating companies. Those companies are large Indian retailers like Aditya Birla Retail and Reliance Retail, large transnational retail and wholesale companies like Metro Group and WalMart and transnational food processing companies like McCain and PepsiCo. The FCP regions are spread across several Indian states, where the participating companies have actively been sourcing fruits and vegetables directly from farmers. Each FCP region forms a production cluster of selected crops, which are targeted by BCS based on the high preference of retailers and processors.

The core of FCP is the transfer of agricultural know-how from "project officers" to "project farmers". Project officers guide the farmers through the growing season and advise them on varieties, fertilisers and pesticides to ensure the demanded quality of the crop. In return, farmers are expected to exclusively use Bayer products as production inputs. Farmers that participate in FCP and fulfil BCS's guidelines are included into the BCS farmer database. This database is a powerful tool for the framing process because it is shared with retailers and processors, who use it to choose farmers for their sourcing. In the sourcing process, the food companies' procurement officers arrange non-binding purchase agreements with the farmers. The actual purchase takes place after negotiations. While the purchase agreements normally indicate a low level of coordination (see Fig. 1), the framing of the processes in Bayer's downstream areas of the value chain should guarantee the implementation of the demanded standards and prevent overflows.

The BCS benefit from the FCP is an increased market share in agrochemicals. Upgrading the farmers through advisory services is not the only aim. The main idea behind FCP was for BCS to develop into a service provider for food retailing and food processing companies and to establish links between farmers and corporate buyers. As framing costs (in terms of cash and effort) are very high when sourcing from smallholders, the partial outsourcing of the framing to BCS can be very attractive. The benefits for the farmers are the ability to supply a larger number of buyers, the potential to save costs for crop treatment due to the adjusted pesticide dosages and potentially higher income due to better harvests.
Beyond that, FCP does not have any other major benefits for the farmers. Still, the costs (e.g. for transportation) and risks (e.g. crop failure) are to be taken by the farmers. The linkages between farmers and their new buyers are quite weak. Furthermore, the farmers do not have any advantages in price stability, and prices are not considerably higher than those paid by traditional buyers. Therefore, the costs of negative externalities (overflows) remain for the farmers.

Even though the programme has been a success, it seems like its attractiveness for retail companies is slowly starting to decline. Due to the now longer presence of once new companies in the sector, transnational and domestic supermarket chains and food processors are deepening their own network embeddedness and, at the same time, develop their own knowledge and strategies for sourcing fresh produce from farmers. Those companies emancipate themselves from BCS. Their need to outsource parts of the framing process seems to decline. Some companies, such as Walmart India, are directly integrating into their own company the tasks BCS once performed. They sometimes even hire exactly the same staff. Thus, they can coordinate the value chain more directly. Furthermore, they want to make sure that they set themselves and the sourced farmers apart from those that are involved in FCP. As a senior official in Walmart India's sourcing department expressed in an interview in 2012: "This [FCP] programme is driven by our sourcing initiative [...]. After some time, we realized that Bayer was doing exactly the same thing for every company, while we thought it is an exclusive programme. That is why we are now introducing our own package of practices to our farmers." By doing so, Walmart India wants to prevent positive externalities in which other companies may profit from their activities of framing the value chain.

As said before, FCP determines the farmers' inclusion in or exclusion from the companies' value chains through the selection of farmers by BCS. The selection criteria include a minimum land holding size of $0.4 \mathrm{ha}$, irrigation facilities, literacy, access to a mobile phone and a certain "business sense". Such criteria are hard to fulfil for many smallholders. Additionally, the programme is highly selective due to three more reasons: (1) spatial selectivity - the programme is implemented only in certain regions, (2) crop selectivity - only crops that are of the biggest corporate interest are integrated and (3) selectivity of agricultural practices - the farmers only receive information about Bayer products and only a limited range of agricultural practices is applied, while traditional farming methods and local crops are neglected.

Although the vertical integration of smallholders in the scheme is quite weak (see Fig. 1), Bayer's ability to include only selected farmers manifests power. It is used to implement their definition of what is good agricultural practice as part of the framing and value capture. Smallholders lacking irrigation and basic education facilities or farmers in more remote regions have the highest need; however, they are excluded. Consequently, the approach has a limited 
developmental scope. The relationships between the different actors in the FCP are not characterised by a linear structure, it is rather a network. It is a triangle between farmers, Bayer and retailers or food processors with strong interdependencies to other actors like agri-input dealers, traditional middlemen or Bayer's rival businesses, which also provide advisory services to farmers.

This triangle may result in a power imbalance. Today farmers still have the option to supply the traditional food trading system. If the market shares of the retail and food processing companies grow and if their framing activities prevent overflows effectively, it can result in a strong dependence of the farmers on those companies. At the same time, a growing market share would also cause stronger implications for those farmers who are excluded from these sourcing networks. The case study shows how input providers gain the power to implement the rules of the market. In other words, input providers frame the trade conditions. This gives them the possibility to implement their own agenda in the framing of the market, while the potential overflowing costs stay mainly with the farmers.

\subsection{Case study 2: SAP's virtual cooperatives in West Africa}

The African Cashew Initiative (ACi) was launched in 2009 and is funded among others by the German Federal Ministry for Economic Cooperation and Development (Bundesministerium für wirtschaftliche Zusammenarbeit und Entwicklung - BMZ). It aims to strengthen the global competitiveness of cashew farmers in Benin, Burkina Faso, Côte d'Ivoire, Ghana and Mozambique. The initiative's goal is to tackle smallholders' constraints through an increase of yields and product quality by improving farming techniques and entrepreneurial practices, access to markets and increasing regional processing. The project is implemented by the German development agency GIZ (Deutsche Gesellschaft für Internationale Zusammenarbeit), the regional business association African Cashew Alliance and the two NGOs Fair Match Support (Netherlands) and Technoserve (USA). Twelve contributing partners from different sectors like financing, (e.g. Bank of Africa, Ecobank), agricultural extension services and technology (SAP) and food companies (e.g. Kraft Foods, Intersnack) are engaged in the project via public-private partnerships (PPPs). The variety of partners and the inclusion of NGOs demonstrates the importance of NGOs for inclusive agribusiness models - actors which are explicitly included in the GPN approach.

The German company SAP is the world leader in business software. In the project, SAP explores how applications for smartphones can strengthen smallholders' and processors' market linkages. As Berndt and Boeckler (2009:543) emphasise, "sociotechnical devices involving material elements, such as warehouses or computer screens, and procedures, such as price negotiations or auctions, that allow dis- tanced exchange" are one of the decisive factors of framing. SAP's activities within ACi focus on linking the formal and informal parts of the cashew, cocoa, shea and coffee value chains through reliable data collection and real-time transmission. Its aim is a technological upgrade of the buying station agents (BSA), which capture each transaction with farmers and buyers via smartphone. This "virtual cooperative" approach results in increased product traceability and more efficient value chain coordination as it gives insights to the typically non-transparent processes at the bottom of the value chain. As such, the provision of reliable data and traceability of the goods is a means of framing. Or as Callon (1998:258) wrote that "the devices that allow us to visualize the existence of the externalities play a crucial role in this descriptive process. They play a potent part in the formation of the groups concerned and in the growth of their self-awareness [...]." Such devices can help to overcome the lack of embeddedness of agribusinesses in the communities from where they source their products. For SAP, this PPP offers an interesting business opportunity. The company already covers the formal sector with business solutions, and thus ACi provides the possibility to develop a co-financed and co-innovated software for the collection of data at the bottom of the pyramid.

The software works with a barcode system via smartphones. The phones are used at the buying stations by the BSA when farmers deliver and when trucks pick up produce. The BSAs have a personal username and password. Every farmer who delivers to the buying stations can participate in the system. Their names, addresses, membership codes and additional information are saved on the smartphones. At the buying stations, every farmer's cashew delivery is weighed, the produce is sacked (which is equipped with a barcode) and the farmer is paid. All transactions are registered via the smartphone application and synchronised to a server, from where the managerial staff of each organising entity can query online reports via a desktop solution. By using smartphones, transactional overviews can also be provided to farmers at any time. Four piloting partners with 51 buying stations in Ghana and Burkina Faso participated in the 2012 piloting cycle. Data of 5000 farmers was collected and 8500 tons of cashew and shea nuts totalling 10000 transactions were captured via the mobile application. Each farmer and sack of cashews can be linked to one another in a database. The digital overview of transactions and the traceability make it possible to find the source of overflows (e.g. a lack of standard compliance). The adoption of the prototype showed that it is possible to support the integration of smallholders via mobile applications. Furthermore, financial services can be included. On the mobile devices, current balances of delivered produce, pre-payment, financing, input management and micro-credits can be displayed. The integration of financial services offers the opportunity to obtain a formal identity by having a digital proof of income. Supplementary to these functionalities, a text message 
information service provides the farmers with agricultural extension services (e.g. market and weather information). As such, it has the potential to be a tool that helps the framing of trade as well as financial relationships. The interviews with BSAs and farmers showed that the people involved were particularly enthusiastic about having modern technology at hand. The advantages of the smartphone application for the three different stakeholders: (1) organising entities, (2) BSAs and (3) farmers, identified during the 2012 evaluation can be summarised as follows:

1. Organising entities (e.g. cooperatives and buyers) were identified as the main beneficiaries. The desktop application provides them with possibilities for overview, administration, analysis and planning. They also help to stabilise the network embeddedness. The data captured permit insights to the typically non-transparent processes (e.g. buying patterns, distribution of productivity and effects of financing gaps, the interdependence between price fluctuations and offers). Hence, these stakeholders can improve their logistics and planning for future contracts. In addition, the financing modalities in the application allow for the tracking of the spent money (especially for input and financing). This means that the data gives the users the possibility of framing parts of the value chain that were beyond their knowledge and control before.

2. BSAs have access to technology that improves their status and digital inclusion. The automatic price calculation based on the broadcasted price and digitalisation of data leads to more trust and improves the relationships between farmers and cooperatives on one side and between the BSAs and the buyers on the other side. Different collaborators clearly announced that the application will most likely increase sales and consequently bring an increase in commission. Furthermore, sack and stock information facilitates better logistics. Altogether, this makes the application a strong tool for upgrading the BSAs.

3. Farmers are now able to get reliable transaction overviews. The price broadcast and the automatic price calculation assure an equivalent price for every farmer. The combination with a text message information service can decrease the information asymmetry and improve farmers' bargaining power. It prevents overflows that are often caused by dishonest middlemen. In the future, the collected transaction data could provide farmers with proof of income for financial institutions. This has the potential to overcome their current lack of creditworthiness. However, it could also be used to frame the trade in a way that ends the informal business and leads to the development of smallholder taxpayers.

Traceability along the value chain all the way down to the farmer can be established with the barcode system. Bene- fits of traceability are standard compliance, quality control and premium payments. This means that framing, in parts of the economy that are normally resistant to framing efforts due to their informality, is possible. Interviewed BSAs and field support staff did not perceive tracing back to the individual farmer as a major benefit. Findings show that traceability becomes relevant once quality premiums are rewarded. It is specifically relevant to (standard-driven) export markets. Although the underlying non-binding purchase agreements are connected with a low degree of vertical integration (see Fig. 1), the broad implementation of such a scheme would prevent overflows as it increases the pressure to fulfil standards and minimises the possibilities to bypass certification obligations. The framing of downstream activities in the value chain via the smartphone application enables better coordination within the value chain. The device has a similar effect as shown in the activities of the Bayer case study. Framing may contribute to a stronger enforcement of overall modes of governance that will standardise the hitherto more fragmented and variegated forms of coordination. Thus, it has the potential to frame the on-the-ground governance processes in a way that it aligns them to the typology of forms of governance in the GVC approach (see Gereffi et al., 2005).

Just like in the first case study, there are preconditions to participate in the scheme. During the piloting phase, the main condition for participation is a sufficient degree of organisation. Accordingly, SAP selects farmer organisations as early adopters. These organisations select the farmers that are allowed to participate. One of the long-term goals is to help non-organised farmers to organise themselves via the software in so-called "virtual cooperatives". Smartphones (see Carmody, 2012 for a discussion of the impacts of mobile phones on development) are used at buying stations; therefore, one person at the buying station has to be able to read targeting thus a semi-literate group of end-users. This incorporates a stronger dependence on the BSA for illiterate farmers. However, it still may improve the transparency of the many informal businesses at the bottom of the value chain and help companies to frame these areas in order to overcome barriers that are often associated with smallholder inclusion in value chains.

\section{Conclusions}

The processes of globalisation and a resurrected interest in agriculture have caused growing interest in smallholders in the global South by scholars, companies, governments and development agencies. Smallholders are not only discovered as a point of action for poverty reduction, but also as a widely untapped resource for the sourcing of high value crops and the sale of agricultural inputs and services. This has resulted in a huge variety of projects implemented by companies, NGOs, development agencies or projects undertaken in PPPs. Although all of these actors may potentially 
influence the value chains' governance structures, the analysis of agri-food value chains often stresses that lead firms determine those structures. In contrast, the potential influence of other companies, such as input or technology providers, on governance has been widely neglected. With the two case studies presented in this paper, we tried to address this lacuna. Both case studies show how the new wave of interest results in changed actor constellations. Smallholders that only used to have connections to local buyers get embedded in complex global networks. These global networks come along with standards and conditions that make the farmers a framing object. Both case studies show how companies, and not only the lead firms, can shape the governance structures of a value chain. They can enforce the framing of the value chain due to the services (or devices) that they provide. This is strongly linked to the discussion of value chain inclusion/exclusion because the provision of such services and products is very selective.

In both case studies, the distribution of information is an important mean to improve business opportunities with smallholders. Furthermore, both schemes aim at an enhanced network embeddedness of the agribusiness in the farming communities. The FCP programme aims to upgrade smallholders and to integrate them into value chains through information exchange between the potential buyers of produce and Bayer. Bayer's strategy is the direct change of governance structure in order to strengthen the influence of corporate buyers such as Bayer. Here the buying companies outsource parts of the framing process to Bayer.

SAP's virtual cooperative is a technical tool that can be used to frame the trade with agricultural produce. Its goals are a technological upgrade of the farmer organisations and a better integration of the informal sector in the GVCs. It does not change the governance structure directly, but provides the different stakeholders with more information about the processes within the value chain in real time. This new transparency opens the black box at the bottom of the value chain for companies and provides them with knowledge about externalities and the information they need to frame the value chain. This makes smallholder value chain inclusion more attractive. Traceability schemes increase the pressure to fulfil standards and enforce the implementation of overall modes of governance that replace the hitherto more fragmented and variegated forms of coordination. Thus, it can prevent overflows and enforce the framing process. Ultimately, it may result in value chain structures that are very consistent with the forms of governance in the GVC approach.

The GVC/GPN approach is useful for analysing the structure of value chains in terms of changes in governance or coordination, value adding and capture and the embeddedness of different stakeholders. Both the GVC and GPN approach have advantages and disadvantages in terms of their applicability for the analysis of smallholders in global agri-food networks and their potential connectivity to the practical discussion about value chains as a development concept. The GVC concept is much more striking in terms of categorising forms of governance that can easily be transferred into applicationoriented approaches, which may lead to a high performativity of the concept. However, its cut-and-dried categorisation does not reflect the manifoldness of governance structures in the field. It misleads by neglecting the potential power of input providers. The concepts of governance and coordination sometimes fall short in analysing the different forms of influence that various actors in the value chain possess. The analysis of the case studies shows how the activities and devices of input and technology providers frame relationships and trade channels in value chains. Consequently, they influence the governance structure of the respective value chains. In particular, the SAP case study showed how the rules of the market might be changed through the introduction of an information system that enables companies to prevent overflows. The concept of framing/overflowing proved to be a meaningful amendment of the GVC or GPN framework.

Acknowledgements. The financial support of the German Academic Exchange Service (DAAD) for field work in India is gratefully acknowledged. Furthermore the authors thank the ACi team of (former) SAP Research, today SAP SE, Products \& Innovation, for the collaboration.

Edited by: B. Korf

Reviewed by: two anonymous referees

\section{References}

Berndt, C. and Boeckler, C.: Geographies of circulation and exchange: constructions of markets, Prog. Hum. Geogr., 33, 535551, 2009.

Berndt, C. and Boeckler, C.: Performative regional (dis)integration: transnational markets, mobiel commodities, and bordered North - South differences, Environ. Plann. A, 43, 1057-1078, 2011.

Callon, M.: An essay on framing and overflowing: economic externalities revisited by sociology, in: The Laws of the Markets, edited by: Callon, M., Blackwell, Oxford, 244-269, 1998.

Callon, M.: What does it mean to say that economics is performative?, in: Do Economists Make Markets? On the Performativity of Economics, edited by: MacKenzie, D., Muniesa, F., and Siu, L., Princeton University Press, Princeton, NJ, 311-357, 2007.

Carmody, P.: The Informationalization of Poverty in Africa?, Mobile Phones and Economic Structure, 8, 1-17, 2012.

Coe, N.: Geographies of production II: A global production network A-Z, Prog. Hum. Geogr., 36, 389-402, 2011.

Coe, N. M., Dicken, P., and Hess, M.: Global production networks: realizing the potential, J. Econ. Geogr., 8, 271-295, 2008.

Dannenberg, P.: Neue Antworten von lokalen Akteuren auf Zwänge in internationalen Wertschöpfungsketten, Geogr. Z., 99, 237255, 2011.

Dannenberg, P. and Nduru, G.: New Challenges and Realities in International Value Chains - Analysing the Proliferation of Standards beyond the Exclusion Debate, Tijdschr. Econ. Soc. Ge., 104, 41-56, 2013. 
FAO - Food and Agriculture Organization: Smallholders in Global Bioenergy Value Chains and Certification, Environment and Natural Resources Working Paper No. 50, Rome, 2011.

FAO - Food and Agriculture Organization: The State of Food and Agriculture 2012 - Investing in Agriculture for a better future, Rome, 2012.

Gereffi, G., Humphrey, J., and Sturgeon, T.: The governance of global value chains, Rev. Int. Polit. Econ., 12, 78-104, 2005.

Germain, C.: Traceability implementation in developing countries, its possibilities and its constraints - A few case studies, ftp://ftp. fao.org/es/esn/food/traceability.pdf (last access: 2 January 2013), 2003.

GIZ - Deutsche Gesellschaft für Internationale Zusammenarbeit GmbH: Growing Business with Smallholders - a Guide to Inclusive Agribusiness, Bonn and Eschborn, 2012.

Goffmann, E.: Frame Analysis: an essay on the organization of experience, Northeastern University Press, Chicago, 1971.

Government of India: Agricultural Census Data Base, http:// agcensus.dacnet.nic.in (last access: 14 January 2012), 2010.

Hammond, A. L., Kramer, W. J., Katz, R. S., Tran, J. T., and Walker, C.: The Next Four Billion: Market Size and Business Strategy at the Base of the Pyramid. IFC - International Finance Corporation, WRI - World Resources Institute, Washington DC, http://pdf.wri.org/n4b_full_text_lowrez.pdf (last access: $29 \mathrm{Au}-$ gust 2013), 2007

Henderson, J., Dicken, P., Hess, M., Coe, N., and Yeung, H. W. C.: Global production networks and the analysis of economic development, Rev. Int. Polit. Econ., 9, 436-464, 2002.

Hess, M.: Spatial' relationships? Towards a re-conceptualisation of embeddedness, Prog. Hum. Geogr., 28, 165-186, 2004.

Hough, P. A.: Disarticulations and commodity chains: cattle, coca, and capital accumulation along Colombia's agricultural frontier, Environ. Plann. A, 43, 1016-1034, 2011.

Kubzansky, M., Cooper, A., and Barbary, V.: Promise and Progress: Market-Based Solutions to Poverty in Africa, Monitor Group, http://web.mit.edu/idi/idi/Africa-\% 20PromiseAndProgress-MIM.pdf (last access: 14 December 2012), 2011.

Lee, J., Gereffi, G., and Beauvais, J.: Global value chains and agrifood standards: Challenges and possibilities for smallholders in developing countries, P. Natl. Acad. Sci. USA, 109, 1232612331, 2012.
Oro, K. and Pritchard, B.: The evolution of global value chains: displacement of captive upstream investment in the Australia-Japan beef trade, J. Econ. Geogr., 11, 709-729, 2011.

Ouma, S.: Global Standards, Local Realities: Private Agrifood Governance and the Restructuring of the Kenyan Horticulture Industry, Econ. Geogr., 86, 197-222, 2010.

Ponte, S. and Gibbon, P.: Quality standards, conventions and the governance of global value chains, 34, 1-31, 2005.

Prahalad, C. K.: The Fortune at the Bottom of the Pyramid: Eradicating Poverty through Profits. Pearson Education, Upper Saddle River, New Jersey, 2006.

Prahalad, C. K.: Bottom of the Pyramid as a Source of Breakthrough Innovations, J. Prod. Innovat. Manag., 29, 6-12, 2012.

Trebbin, A. and Franz, M.: Exclusivity of private governance structures in agro-food networks: Bayer and the food retailing and processing sector in India, Environ. Plann. A, 42, 2043-2057, 2010.

Trebbin, A. and Hassler, M.: Farmers' producer companies in India: a new concept for collective action?, Environ. Plann. A, 44, 411427, 2012.

UNDP - United Nations Development Programme: Creating Value for all - strategies for doing business with the poor, www.rw.undp.org/content/dam/rwanda/docs/povred/RW_rp_ Creating_Value_for_All_Doing_Business_with_the_Poor.pdf (last access: 31 October 2014), 2008.

UNIDO - United Nations Industrial Development Organization: Industrial Value Chain Diagnostics: An Integrated Tool, Vienna, 2011.

USAID - United States Agency for International Development: Implementation best practices for value chain development projects, Microreport \#167, www.enterprise-development.org/download. ashx?id=1860 (last access: 2 January 2013), 2010.

Vermeulen, S. and Cotula, L.: Making the most of agricultural investment: A survey of business models that provide opportunities for smallholders, FAO and IIED, Washington DC and London, 2010.

World Bank: World Development Report 2008 - Agriculture for Development, Washington DC, 2007. 